\title{
PARA ENSINAR MACROECONOMIA NA GRADUAÇÃO EM ADMINISTRAÇÃO
}

\author{
TEACHING MACROECONOMICS \\ IN UNDERGRADUATE ADMINISTRATION COURSES
}

\author{
Recebido em: 21/02/2013 - Aprovado em: 30/04/2013 \\ Avaliado pelo sistema double blind review \\ Editora Científica: Manolita Correia Lima
}

\section{ALFREDO BEHRENS alfredobehrens@gmail.com FUNDAÇÃO INSTITUTO DE ADMINISTRAÇÃO}

\begin{abstract}
RESUMO
Pesam contra o interesse dos cursos de graduação em administração, na disciplina de macroeconomia: o baixo peso das questões no Enade e o longo tempo que transcorre entre a formação do estudante e a demanda profissional pelo entendimento da macroeconomia. No entanto, o entendimento de macroeconomia desenvolve a aptidão do aluno pelo pensamento estratégico e tático, além de formar melhores cidadãos. Neste artigo, mostro como, propiciando uma participação mais ativa dos alunos no aprendizado, consegui neutralizar a resistência. Começou-se por meio de trabalhos de casa com o fim de desenvolver um melhor entendimento factual e emocional do significado do desemprego para as famílias e a sociedade. Vídeos e fotografias da época da Grande Depressão e as contemporâneas na Europa, como o movimento dos Indignados da Espanha e a Geração à Rasca de Portugal e entrevistas com desempregados serviram ao propósito. Demanda e Oferta Agregadas foram apresentadas antes das contas nacionais e estas logo depois do modelo macroeconômico para economias fechadas, seguindo então com o modelo para as economias abertas, os ciclos econômicos, inflação e a análise do Plano Real, inclusive com vídeos sobre o período de hiperinflação. Fechou-se o curso com um role-playing-game no qual os alunos chamaram a uma conferência de imprensa para opinarem sobre a política expansionista do governo durante o primeiro semestre de 2012 , com base na posição do grupo de interesse por eles escolhido.
\end{abstract}

Palavras-chave: ensino de macroeconomia; Administração; participação do aluno; role playing game, RPG.

\begin{abstract}
The relative unimportance ENADE (the National Student Performance Exam) places on macroeconomics coupled with the long time that elapses between graduation and the professional demands for its understanding combine to act against the interests of the discipline undergraduate administration courses. However, an understanding of macroeconomics develops students' aptitude for strategic and tactical thinking and shapes better citizens. This paper demonstrates how providing opportunities for students to participate more actively in learning can neutralize their resistance. This began through analyzing homework tasks in class, with the aim of better understanding the factual and emotional meanings of unemployment to families and society. Videos and photographs of the Great Depression and the contemporary ones in Europe, including the Indignados and Geração à Rasca movements, in Spain and Portugal, respectively, also served the purpose. This was followed by Aggregate Demand and Supply, presented before the national accounts, which in turn came soon after the macroeconomic model for closed economies, followed by the model for open economies, business cycles, inflation and an analysis of the Real Plan; including videos on the period of hyperinflation. The course closed with a role-playing game in which students called a press conference to express their views on the expansionist policies of the Brazilian government during the first half of 2012, from the position of the interest group of their choice.

Keywords: teaching macroeconomics; administration; student participation in learning; role-playing game; RPG.
\end{abstract}




\section{INTRODUÇÃO}

Ensinar Macroeconomia para alunos de graduação em administração é tão dificil quanto necessário fazê-lo corretamente. O problema é complicado ainda mais porque os alunos sabem que as noções de Economia, como um todo, têm pouco peso no exame do Enade ${ }^{\text {r; }}$ e porque o futuro jovem gestor não ocupará, no início da sua carreira, posições que lhe permitam fazer uso do seu entendimento de macroeconomia de forma a ter algum impacto na condução dos negócios sob sua responsabilidade. Daí que os alunos sintam que seu interesse pela matéria de Macroeconomia poderia ser sacrificado em prol de um melhor entendimento de disciplinas mais operacionais, tais como Finanças, Marketing e outras.

Conta a favor do interesse dos alunos em Macroeconomia a enfática atenção que, naturalmente, os temas macroeconômicos têm nos noticiários e nas conversas dos adultos mais experientes. Por isso acho que o enlace pedagógico para despertar o interesse dos alunos no entendimento de macroeconomia deva passar pelo engajamento da disciplina na explicação do cotidiano da gestão macroeconômica e de suas repercusões nas empresas e nos negócios.

Em vez de começar pelas contas nacionais ou ciclos econômicos, a atenção no início do curso ficou centrada na principal razão da raiz histórica da macroeconomia: o combate ao desemprego. Para tanto, foi introduzido o entendimento do significado social, emocional e político de um alto índice de desemprego. Para isto pedi que os alunos buscassem identificar a autora (Dorothea Lang) na fotografia "Mãe Migrante", de 1936, e analisassem a relevância social da sua sequência de fotografias assemelhadas. Posteriormente, pedi que os alunos buscassem entender por que Dorothea Lang foi financiada por um órgão do governo americano para retratar o caos social provocado pelo desemprego, e em sequência, que buscassem saber do objetivo econômico da política do New Deal americano. Em 2012 cada aluno fez uma apresentação multimídia de uma

1 O Exame Nacional de Desempenho de Estudantes (Enade) avalia o rendimento dos alunos dos cursos de graduação. 
pessoa desempregada, focando nas consequências pessoais e familiares do desemprego.

Também foi pedido aos estudantes que pesquisassem para explicar por que haveria mais descendentes de africanos nas seleções de futebol do norte da Europa participando da copa da África do Sul, do que nos países mais próximos da África, como a Grécia, Itália, Espanha e Portugal. Esta tarefa ajudou a introduzir o papel dos investimentos, da pesquisa e desenvolvimento do dinamismo das economias, e na sua capacidade em atrair imigrantes; sugerindo que os chamados PIIGs teriam sido menos dinâmicos do que os países do norte da Europa e daí a falta de descentes de africanos nos seus times.

Esta tarefa ajudou a introduzir a compreensão sobre a contemporaneidade da crise financeira na Europa, que foi abordada por meio de vídeos e discussões sobre o desemprego na Europa, inclusive sobre o Movimento dos Indignados na Espanha, e sobre os saques em Londres.

Posteriormente, foram discutidas as implicações da discriminação no mercado de trabalho, em particular contra mulheres e negros no Brasil.

Estes temas ocuparam as primeiras três semanas de aula, mas com eles foram assentadas as bases emocionais e políticas para situar Macroeconomia na época contemporânea e entender o porquê do objetivo central da política Macroeconômica: estabilização de preços com pleno emprego e crescimento.

Desta forma foi conduzido o ensino de macroeconomia, sempre ancorado na realidade, tanto a contemporânea quanto a histórica. A Macroeconomia, propriamente dita, foi apresentada pela interação da oferta e demanda agregadas, fazendo assim um elo instrumental com o ferramental aprendido em microeconomia, com temas como a Lei da Oferta e da Demanda. Apesar das boas razões de Barro (1994, p. I) para não recorrer aos modelos de Demanda e Oferta Agregadas, ao ensinar Macroeconomia, esses modelos tem uma forte apelo pedagógico (KENNEDY, 2008; Weerapana, 2003; Weels, 20Io). Primeiro, foi apresentada a abordagem clássica, posteriormente a keynesiana, e discutidas as eficácias relativas das políticas montária e fiscal em relação às situações de pleno emprego. Somente após, foram apresentadas as Contas Nacionais e discutidas as 
políticas macroeconômicas em economias fechadas e abertas, sendo que, por último, foram abordadas as contribuições mais modernas em torno da teoria das expectativas racionais dos agentes econômicos e seu impacto na eficácia das políticas macroeconômicas.

O ensino de marcoeconomia foi encerrado com uma análise do período de hiperinflação no Brasil e o papel de uma âncora cambial no sucesso do Plano Real. Mesmo esta parte do curso, sobre meados nos anos noventa, cobre uma época na qual os alunos teriam em torno de ro anos e por isso foi apoiada em vídeos da época, interpretando o cotidiano das pessoas num regime inflacionário.

Na última semana do curso, e como parte da prova final, foi organizado um jogo. Este jogo, na verdade é um jogo de interpretação de papéis (RPG), consistiu em que os alunos adotassem a ótica dos diferentes agentes econômicos para posicionarem seus argumentos em relação à gestão da política macroeconômica do governo brasileiro no mesmo primeiro semestre de 20I2. Para conter a expressão dos diferentes pontos de vista, a posição de cada grupo devia ser expressa dentro da moldura de uma conferência de imprensa. ${ }^{2}$ Como o jogo implicava em pesquisa, parte escrita e apresentação, ele também permitiu testar a eficácia do aprendizado da matéria e ainda despertar nos alunos o estado de alerta necessário para interpretar os argumentos espelhados na imprensa.

Acredita-se que o resultado tenha sido muito positivo, tanto pelo aprendizado demostrado pelos alunos, quando pelos próprios depoimentos deles, disponível em um vídeo de onze minutos (BEHRENS, 20I2a).

No restante do artigo serão explicadas as razões pelas quais o ensino de macroeconomia precisa ser diferenciado daquele que se dá aos alunos de graduação em Economia, embora os livros textos e frequentemente os professores sejam os mesmos. Foi feita uma revisão do estado do conhecimento em outros países e recolhidas as experiências deles.

\footnotetext{
2 O jogo aplicado aqui não é um jogo, propriamente dito, no sentido de que não leve a resultados de perdas ou ganhos, seguindo uma estrutura rígida, senão um jogo de interpretação dos papeis de agentes econômicos, sendo mais próximo de uma simulação. Em inglês, estes jogos são conhecidos como "role playing games" e frequentemente são abreviados pelo acrônimo RPG. Agradeço à professora Roselí da Silva o comentário referente à necessidade de esclarecer a diferença entre um jogo e uma simulação.
} 
Posteriormente, é apresentado o método, RPG, ao qual recorre-se para estimular a adoção por parte dos alunos das diferentes perspectivas e assim aguçar entre eles o entendimento de que não há uma política econômica perfeita, senão políticas econômicas, que resultam mais ou menos palatáveis aos agentes em função de seus interesses e horizontes que levam em consideração. 


\section{A INSERÇÃO DA ECONOMIA NOS CURSOS DE ADMINISTRAÇÃO}

Com o crescente interesse por gestão, está havendo uma queda de interesse pelos cursos de Economia no mundo inteiro. Na Austrália, a preocupação com a queda na procura por cursos de Economia já existe há quase duas décadas (millmow, 1993). No Brasil, já era notícia em 1996 (Isto É Dinheiro). A tendência é tão marcante que Healeya (2006) perguntava-se se haveria algum papel para a Economia no ensino em cursos de Administração.

A Associação Australiana de Economia liderou uma enquete na qual as explicações pela falta de interesse apontavam a Economia como carecendo de senso prático (AZZALINI; HOPKINS, 20IO). Não raro, na Austrália já há até resultados com experiências dirigidas a reduzir o conteúdo de Economia de dois para um semestre, combinando Micro e Macroeconomia. No entanto, o resultado da redução seria contraindicado porque os alunos que cursaram dois semestres de economia tiveram um melhor desempenho, em Economia, bastante superior aos que cursaram apenas um (GUEST; VECCHIO, 2003). Inclusive publicações prestigiosas, na área de Administração, acolhem artigos sugerindo que a Macroeconomia tem muito a contribuir no desenvolvimento do pensamento estratégico e tático de um CEO (NAVARro, 2006).

Como então manter o interesse dos alunos de graduação em Administração em relação à disciplina de Economia, que tem a contribuir, porém não parece entusiasmá-los suficientemente?

Como resposta, pareceria favorável tornar o ensino mais ancorado na realidade como forma de facilitar a interpretação do significado por parte dos alunos (LORD, 1997). Naturalmente, isto exigiria um maior recurso a textos escritos por autores nacionais, no lugar dos livros-texto traduzidos. Mas, para não se perder tudo o que se perderia rejeitando os livros-texto de origem estrangeira, pode-se complementá-los com o uso mais intensivo, em sala de aula, de informações com cores mais locais. Não apenas com as notícias imediatas, mas também se utilizando outras formas de informar aos alunos, como o recurso a clipes de cinema (LEET; HOUSER, 2003) e documentários (MATEER; LI 2008). 
Por outro lado, para o aprendizado ser menos passivo, e mais eficaz, é necessário fazer o aluno participar mais ativamente do processo de ensino (WATTS; BECKER, 2008), (HARMONA; LAMBRINOS, 20I2). esta participação pode ser por meio de modelos de simulação (WHEAT JR. 2008), por meio da escrita de um informe após um exercício (CARTWRIGHT; STEPANOVA, 2OI2), ou mesmo participar mais ativamente em um role playing game (BUCHs; BLANCHARD, 20II). Esta preocupação com formas mais ativas de ensino de economia são compartilhadas no Brasil por Silva e Batista Ferreira (20I0).

\section{POR QUE O TEMA MACROECONÔMICO É MAIS DIFÍCIL DE ENSINAR NA GRADUAÇÃO EM ADMINISTRAÇÃO?}

Os alunos da graduação em Administração parecem chegar à universidade com menos paciência em relação à defasagem entre causa e efeito, tão própria da gestão macroeconômica. Isto poderia ser uma característica geracional (SWEENEY, 2006), mas também poderia ser mais específica dos alunos em Administração, mais focados que são em uma relação imediata entre causa e efeito, própria dos jogos de computadores e do estilo de interação das novas gerações.

Mas, a gestão da política macroeconômica não tem um século de prática e tem menos ainda de acertos. A escassez de acertos não é apenas por falta de consenso quanto aos fundamentos, mas também porque a gestão é o resultado de um paralelograma de forças sociais que se realiza dentro de um marco jurídico que não permite aos gestores um horizonte maior do que o que media até a próxima eleição. Os gestores de política macroeconômica teriam, em média, dois anos pela frente, sendo que alguns dos efeitos desejados das políticas adotadas, i.e. aumento do emprego, poderiam começar a se materializar em três a seis meses, apenas.

Em consequência, na falta de um antenamento adequado entre os formuladores da política, a gestão da crise pode vir com um certo atraso, como foi o caso do Brasil no segundo semestre de 2008, quando se confundiu com uma marola, o que resultou estar mais próximo de um tsunami, resultante da quebra do Banco Lehman (MODÉ, 2008).

Mas a falta de antenamento dos gestores não é necessariamente compartilhada por todos os agentes econômicos, daí que há tantos 
investidores hoje, temerosos com a inflação futura, fruto do excesso de liquidez atual, procurando investir em ativos reais (KONING, 2012). Isto é, as próprias expectativas dos agentes quanto às políticas macroeconômicas também desempenham um papel importante, inclusive porque há assimetria entre os agentes econômicos na formação das expectativas em decorrência de diferentes níveis de acesso à informação e à escolaridade necessária para processá-la. A percepção da existência de assimetrias é uma dificuldade adicional para a clientela das universidades privadas ou de elite, e seria específica de uma geração superprotegida, dentro de uma classe social com pouca interação fora dela (BEHRENS, 20I2B).

Se estas razões não fossem suficientes para dificultar o aprendizado de Macroeconomia entre alunos da graduação em Administração, as apreciações da oportunidade ou eficácia das políticas, tal como veiculadas pelos órgaõs de imprensa, ilustram o viés de quem as expõe ou veicula. Assim, teremos que, diante de uma política específica, aparecerão versões de apoio e outras menos entusiastas. Na maioria das vezes, as opiniões vêm revestidas pela aura de imparcialidade que mereceria ser conferida quanto à declaração de estarem compromissadas com os melhores interesses do país; mas, na verdade, camuflam, já que estas opiniões frequentemente não são tão imparciais quanto pretendem, mesmo aos olhos dos alunos da graduação. portanto, a prática de um exercício de conferência da imprensa (SUTCLIFFE, SD) poderis ser por demais enriquecedora. 
Quadro I Cenário quanto à gestão econômica

Para o Brasil, o cenário econômico internacional, em maio de 2012, era preocupante. A China, que tinha aumentado a taxa de juros para conter o crescimento da economia, foi obrigada a diminuí-la em junho quando verificou que a queda no crescimento seria muito forte.

Por outro lado, os desdobramentos da crise na Europa demoram a desaparecer; e os EUA não saem do marasmo; nem parece haver possibilidade de solução num período eleitoral. Diante de tantas incertezas no exterior e do arrefecimento da demanda chinesa, é natural que a gestão da política econômica brasileira buscasse no mercado interno uma forma de manter o crescimento.

Para isto, o governo, que já tolerava uma desvalorização significativa do Real, também já havia cortado o IPI dos carros e o IOF sobre empréstimos internacionais; já havia modificado o rendimento da caderneta de poupança para permitir juros mais baixos; e, em 21 de maio, anunciou que mais um corte na taxa de juros seria conveniente, desde que o spread dos bancos comerciais diminuísse também. Daí, em 26 de maio, a FSP divulgou que o Ministro Guido Mantega pressionaria os Bancos comerciais para diminuírem suas taxas aos tomadores, entre 30 e 40 por cento, e que ainda assim aumentassem seus empréstimos em quantia igual. Já em $1^{\circ}$ de junho, os Bancos começaram a abaixar seus juros, enquanto que o jornal Valor afirmava, em 8 de junho, que a natureza recessiva dos números dos últimos meses (leia-se, indústria em queda) dificultaria o avanço da inflação.

Porém, há um risco importante de retomada da inflação num momento em que o desemprego está em níveis historicamente baixos e quando se pode contar menos com a concorrência dos produtos estrangeiros devido à desvalorização do Real. Naturalmente, o governo poderia reverter as iniciativas expansionistas se uma tendência inflacionária se manifestasse e se a pressão da opinião pública o exigisse. Mas, qual é a perspectiva de uma queda na taxa de juros para os diversos stakeholders da economia brasileira?

\section{A CONFERENCIA DE IMPRENSA}

Porque as políticas macroeconômicas não são neutras em relação aos efeitos sobre os diferentes agentes econômicos, procurou-se um método que permitisse aos alunos perceberem como os diferentes interesses de curto prazo motivam as posições adotadas em relação a uma política.

Para isto, recorreu-se a um instrumento frequente no mundo dos negócios, que é a conferência de imprensa. Por meio delas os agentes procuram difundir suas posições, com argumentos esboçados de forma persuasiva.

Os alunos tomaram partido de diferentes grupos de interesses e chamaram conferências de imprensa para veicular suas posições.

A tarefa alocada pelo professor procurou, também, estimular os alunos a selecionarem os conhecimentos de macroeconomia de forma a valorizar aqueles que contribuíssem mais ao sustento de sua posição e a colocar em 
prática sua capacidade de apresentar esses argumentos de forma suscinta e persuasiva.

O role playing game (RPG) foi organizado na forma de uma conferência de imprensa chamada pelos diversos grupos de interesse (stakeholders) de uma política econômica do governo. O jogo descreve uma encenação concebida para o final do primeiro curso de macroeconomia de graduação em Administração e Negócios da Faculdade FiA, liderado pelo Professor Alfredo Behrens.

É relativamente fácil identificar os grupos de interesse na política macroeconômica: governos, empresas, consumidores, trabalhadores, Bancos comerciais privados, partidos políticos, aposentados etc. No entanto, é mais difícil para os estudantes assimilarem as razões dos pontos de vista contrastantes sobre os benefícios e as perdas resultantes de uma mudança na política macroeconômica. A dificuldade aparece, em parte, porque os argumentos de stakeholders como Bancos comerciais privados, indústriais ou partidos políticos, são frequentemente apresentados em termos austeros e altruistas, camuflando os interesses subjacentes.

Por estas razões, pensou-se que um role playing game poderia ajudar aos alunos a investigar questões referentes ao equilíbrio macroeconômico de uma maneira interessante, salientando os diversos pontos de vista sobre uma mesma situação: as diferenças de posições quanto à resposta dos diferentes stakeholders em relação a uma opção de gestão econômica feita pelo governo do Brasil, desde o começo de 2012, mas que ganhou forma mais definida em maio de 2012, escassas três semanas antes do role playing game. Isto significa que a discussão sobre a virada de política econômica era um assunto efervescente à epoca do jogo, meados de junho de 2012.

O cenário da situação internacional e a resposta de política econômica foram apresentadas na caixa acima, numa versão esquemática, e fornecidas aos alunos pelo professor, inclusive com os enlaces necessários para se aprofundarem nas notícias. Foi dada aos estudantes uma semana para prepararem seus argumentos, os quais foram expostos em sala de aula no dia I8 de junho de 20I2. Entre o desafio e as conferências de imprensa, os alunos puderam se reunir com o professor em mais uma aula de dupla 
duração, durante a qual foi discutida a estratégia a ser seguida em cada grupo.

As mesmas instruções detalhadas quanto ao jogo, entregues aos alunos, são apresentadas a seguir. Estes foram convidados a trabalhar em duplas. Cada uma representando um interesse (stakeholder). A pesquisa e argumentação do grupo deveria ser orientada de forma a assumir o ponto de vista da parte interessada.

A lista dos stakeholders possíveis para este jogo encontra-se a seguir. Poderia haver mais, por exemplo, associações de importadores, ou representantes dos agentes negociadores de títulos de renda fixa ou, inclusive, o governo. Houve mais de um grupo que escolheu representar o mesmo ponto de vista e as apresentações foram ordenadas de forma a facilitar a comparação dos trabalhos sobre o mesmo tópico.

Como produto, cada grupo deveria entregar, em sala, no prazo final:

- um comunicado de imprensa

- um pacote (dossier) de informações para a imprensa

- uma apresentação, em 5 minutos, como se fossem stakeholders (partes interessadas, tais como: sindicato dos patronos das indústrias, sindicato de trabalhadores da indústria, ong de defesa dos consumidores, bancos comerciais, aposentados).

\section{INSTRUÇÕES}

A maioria de vocês, em algum momento da vida, presenciou uma conferência de imprensa na TV. Para este trabalho, você terá a oportunidade de realizar uma. Irá, com mais um colega, considerar um problema de política macroeconômica (fornecido no cenário) baseado na perspectiva de um stakeholder (grupo de interesse).

Uma breve atribuição detalhada é apresentada a seguir, por favor leia com muito cuidado. O que está sendo avaliado?

Este trabalho consiste em quatro componentes avaliados, de i a io, com os seguintes pesos:

\footnotetext{
3 As instruções foram baseadas num role playing-game sobre comércio internacional do Economics Network do Reino Unido. Disponível em: http://www.economicsnetwork.ac.uk/international/teaching
} 
- $\quad$ um comunicado de imprensa (10\%);

- um pacote de imprensa (40\%);

- uma apresentação (50\%);

- um diário das tarefas realizadas pelos integrantes do grupo (o\%)

\section{DEFINIÇÃO DE CADA PRODUTO A SER ENTREGUE PELO ALUNO}

$\mathrm{O}$ comunicado de imprensa (press release) - O comunicado de imprensa deve assumir a forma de um único lado de página $\mathrm{A}_{4}$, que é para ser distribuído na conferência de imprensa, uma cópia por aluno e outra para o professor. O comunicado de imprensa deve identificar as principais questões que suportam as políticas que o grupo propõe e aquelas às que se opõe. Deve ter um título sugestivo que oriente os jornalistas quanto à confecção de uma manchete para a notícia. $O$ dossier de imprensa - O dossier de imprensa deve oferecer ao leitor uma análise em maior profundidade de suas opiniões e ponto de vista. Esse pacote inclui material escrito pelo grupo, enlaces para artigos de outras fontes, assim como estatísticas e as fontes de pesquisa para facilitar a tarefa dos jornalistas que quiserem aprofundar ainda mais suas informações. $\mathrm{O}$ dossier de imprensa deve incluir não mais do que 2000 de suas próprias palavras. A chave para um bom dossier de imprensa é que ele seja eficaz. Para isso deve ser informativo e suscinto, como para ser lido por pessoas ocupadas, com pouco tempo para ler.

\section{A APRESENTAÇÃO}

Deve ter no máximo I5 minutos de duração. Neste tempo, você vai argumentar a sua posição sobre a conveniência ou não da política macroeconômica e sugerir alternativas. A apresentação deve ser em PowerPoint ou Prezi. A apresentação que você faz também dever ser entregue ao professor, impressa ou em meio digital (via Moodle). O propósito não é apresentar um argumento equilibrado com prós e contras em relação à política; mas um argumento baseado em um ponto de vista particular, que expresse preocupações específicas, ao mesmo tempo que ofereça sugestões 
de políticas específicas em função das preocupações do grupo que você representa.

Juntamente com a apresentação do dossiê de imprensa, cada grupo deve apresentar um diário do grupo. Ele deve incluir uma lista das responsabilidades de cada integrante do trabalho. O diário também deve incluir um calendário de todas as reuniões da dupla, quem estava presente ou ausente nas reuniões, e por quê. O diário deve ser assinado por todos os membros da equipe, como reconhecimento de que seus conteúdos são precisos, e apresentado juntamente com o pacote de imprensa.

\section{GRUPOS}

Neste trabalho em particular, os grupos foram selecionados pelos alunos e foram limitados a dois integrantes. A dupla decidirá a estratégia mais eficaz para completar esta missão. Provavelmente, envolverá alguma divisão de trabalho, inclusive na fase inicial de coleta de informações. 


\section{CONSIDERAÇÕES FINAIS}

Turmas maiores poderão optar por mais integrantes, permitindo uma maior divisão do trabalho e mais oportunidades de praticar a gestão de trabalho em equipe. Neste sentido, um grupo ideal poderia ter de três a quatro integrantes. Mais integrantes dificultaria a administração do tempo de apresentação, se todos tiverem de apresentar; o que é desejável para aferir o desempenho individual dos alunos. Neste caso, ambos os integrantes do grupo deviam apresentar a posição escolhida, permitindo uma melhor avaliação do trabalho individual por parte do professor. Se o tamanho do grupo for de cinco ou mais participantes, o tempo total alocado para exposição deveria ser consideravelmente maior para que todos participem, e possivelmente acabaria prejudicando, por cansaço, o tempo dedicado ao debate das posições.

O tempo de apresentação levou duas horas e 30 minutos com 15 minutos de intervalo. Se mais tempo tivesse sido disponível, o professor poderia ter agido como o Governo, defendendo a opção pela sua política. No caso, o papel do professor ficou limitado à definição do cenário, caracterizando a política macroeconômica como uma de expansão do crédito e redução da taxa de juros.

Os alunos demonstraram engajamento, disciplina e discernimento na escolha dos argumentos e sua apresentação. Ao lerem os comunicados de imprensa dos outros grupos, ao se ouvirem apresentado e ao discutirem, tiveram oportunidade de apreciar as dificuldades na acomodação de interesses conflitantes e de como a natureza da política macroeconômica, e os interesses dos agentes, molda argumentos econômicos para o que viria a ser uma solução possível.

Como os alunos estudam administração, o jogo permitiu aprimorar a capacidade de trabalharem em duplas, com prazos exíguos e de praticarem o uso de um instrumento de comunicação frequente no ambiente de trabalho, como é o relacionamento com a imprensa. A confecção do próprio Diário a ser entregue junto com o dossier de imprensa, simples como é, 
constitui evidência da necessidade de gerir os resultados de um encontro como, frequentemente, ocorre nas reuniões em empresas.

O trabalho também ofereceu a oportunidade de desenvolver uma ampla gama de habilidades cognitivas: definição de uma estratégia de trabalho, a escolha dos argumentos e das táticas de persuasão, a recuperação, organização e análise da informação, bem como as próprias habilidades de apresentação. Também permitiu desenvolver competências emocionais como empatia, despertando nos alunos uma melhor compreensão quanto às dificuldades do outro em aceitar argumentos que poderiam soar apenas racionais a quem os propõe. Isto aparece claramente num dos depoimentos por parte dos alunos quanto à utilidade do role playing game.

O jogo também promoveu a necessidade dos alunos de assumirem o controle do seu próprio aprendizado, estimulando a responsabilidade pessoal pelo seu sucesso; e induziu os alunos a tomarem partido, a não ver uma aula apenas como uma sessão imparcial de transmissão do conhecimento objetivo.

É frequente entre os professores, na ansiedade por cobrir uma grade extensa, deixar pouco tempo para a expressão dos alunos ou para o uso de material que, como o role playing game, são intensivos em tempo de aula. No entanto, a dedicação percebida nos trabalhos dos alunos, a alegria com a qual se entregaram ao trabalho, e a naturalidade com a qual esgrimiram argumentos teóricos para fundamentarem suas posições, recomenda a adoção de mais instrumentos como este com mais frequência; porque parece haver um trade-off entre cobrir, mais exaustivamente, maior quantidade de temas e perder participação e aprendizado dos alunos. Neste sentido, um role playing game como o proposto, estimula o engajamento dos alunos, permitindo que eles desenvolvam o orgulho em relação ao domínio dos conhecimentos apreendidos. 


\section{REFERENNCIAS}

AZZALINI, P.; HOPKINS, S. What business students think of economics: results from a survey of second year students. Economic Papers, v. 21, n. 1, p.11-17, 2002.

BARRO, R.J. The Aggregate-Supply/Aggregate-Demand Model. Eastern Economic Journal, v. 20, n. 1, p. 1-6, 1994.

BEALS, R.K How to protect your portfolio with 'real' assets. Assets such as gold, energy, and real estate can keep your portfolio ahead of inflation. USNews. New York, 03/04/2012. Disponível em: <http://money.usnews.com/money/personal-finance/ articles/2012/04/03/how-to-protect-your-portfolio-with-real-assets $>$. Acesso em $19 / 06 / 2012$.

BECKER, W.E.; WATTS, M.; BECKER, S.R. Teaching Economics: more alternatives to chalk and talk. Cheltenham-UK: Edward Elgar Publishing Limited, 2006. Resenha de: SILVA, da R.; BATISTA-FERREIRA, N. N. EST. ECON, v. 40, n. 4, p. 967-973, 2010.

BEHRENS, A.(a). Ensino de Macroeconomia na Faculdade FIA de Administração e Negócios. São Paulo: Fundação Instituto de Administração, 18/06/2012. Disponível em: http:// www.youtube.com/watch?v=ULuWQAN7uzE\&feature=youtu.be Acesso em: $21 / 20 / 2012$.

BEHRENS, Alfredo (b). What multinationals miss in emerging markets. Harvard Business Review Blog Network. 31/01/2012. Disponível em: http://blogs.hbr.org/ cs/2012/01/what multinationals miss in em.html. Acesso em: 14/11/2012.

BUCHS, A.; BLANCHARD, O. Exploring the concept of sustainable development through role-playing. The Journal of Economic Education, v. 42, n. 4, p. 388-394, 2011.

CARTWRIGHT, E.; STEPANOVA, A. What do students learn from a classroom experiment: not much, unless they write a report on it. The Journal of Economic Education, v. 43, n. 1, p. 48-57, 2012.

GUEST, R.; VECCHIO, N. Are there Learning Spillovers in Introductory Macroeconomics? International Review of Economics Education, v. 1, n. 1 p. 36-60, 2003.

HARMONA, O.R.; LAMBRINOS, J. Active-learning exercises for principles of economics courses. The Journal of Economic Education, v. 43, n. 2, p.221, 2012.

HEALEYA, N. M. What role for economics in business and management education? Journal of Further and Higher Education, v. 17, n. 3, p. 34-39, 1993.

Economia: cadê os alunos? Isto É Dinheiro. São Paulo, n. edição 461, 19/07/2006.

Disponível em: <http://www.istoedinheiro.com.br/noticias/3109_

ECONOMIA+CADE+OS+ALUNOS $>$. Acesso em: 14/11/2012.

KENNEDY, P. A big picture for teaching macroeconomics principles. Economics Bulletin, v. 1, n.1, p. 1-6, 2008. 
LEET, D.; HOUSER, S. Economics goes to Hollywood: using classic films and documentaries to create an undergraduate economics course. The Journal of Economic Education, v. 34, n. 4, p. 326-332, 2003.

LORD, T.R. A comparison between traditional and constructivist teaching in college biology. Innovative Higher Education, v. 21, n. 3, p. 197-216, 1997.

MATEER, G. D.; LI, H. Movie scenes for economics. The Journal of Economic Education, v. 39, n. 3, p. 303, 2008.

MILLMOW, A. To eke out a marginal existence: economics in business schools. Economic Papers: a journal of applied economics and policy, v. 16, n. 3, p. 88-96, 1997.

MODÉ, L. Marola ou tsunami? O Estado de São Paulo: economia \& negócios. São Paulo, 30/10/2008. Blog José Paulo Kupfer. Disponível em: <http://blogs.estadao.com.br/ jpkupfer/marola-ou-tsunami/>. Acesso em: 14/10/2012.

NAVARRO, P. The hidden potential of "Managerial Macroeconomics" for CEO decision making in MBA programs. The Academy of Management Learning and Education, v. 5, n. 2, p.213-224, 2006.

SUTCLIFFE, M. Simulations, Games and Role-play. In: DAVIES, P. (Ed.). The Handbook for Economics Lecturers, p. 17-20, sem data. Disponível em: http://www. economicsnetwork.ac.uk/handbook/printable/games v5.pdf. Acesso em 14/10/2012.

SWEENEY, R. Millennial behaviors \& demographics. Newark, NJ: University Heights. 2006.

WATTS, M.; BECKER, W. E. A little more than chalk and talk: results from a third national survey of teaching methods in undergraduate economics courses. The Journal of Economic Education, v. 39, n. 3, p. 273-286, 2008.

WEERAPANA, A. Intermediate Macroeconomics without the IS-LM Model. Journal of Economic Education, v. 34, n. 3, p 241-262, 2003.

WELLS, G. Teaching Aggregate Demand and Supply Models. The Journal of Economic Education, v. 41, n. 1, p. 31-40, 2010.

WHEAT Jr., D. The feedback method of teaching macroeconomics: is it effective? System Dynamics Review, v. 23, n. 4, p. 391-413, 2007. 


\section{DADOS DOS AUTORES}

Alfredo Behrens ${ }^{\star}$ alfredobehrens@gmail.com
Doutor em Economia pela Universidade de Cambridge
Instituição de vinculação: Fundação Instituto de Administração
São Paulo/SP - Brasil
Áreas de Interesse em Pesquisa: Liderança, Culturas Nacionais e Gestão.

${ }^{\star}$ Rua João Gomes Xavier, 132 Perdizes São Paulo/SP 05005-020 